2021-06

\title{
Age differences in deliberate ignorance.
}

\author{
Hertwig, Ralph
}

http://hdl.handle.net/10026.1/17531

10.1037/pag0000603

Psychology and Aging

American Psychological Association (APA)

All content in PEARL is protected by copyright law. Author manuscripts are made available in accordance with publisher policies. Please cite only the published version using the details provided on the item record or document. In the absence of an open licence (e.g. Creative Commons), permissions for further reuse of content should be sought from the publisher or author. 
Brief Report

\section{Age Differences in Deliberate Ignorance}

Ralph Hertwig ${ }^{1}$, Jan K. Woike ${ }^{1}$, and Jürgen Schupp²

${ }^{1}$ Max Planck Institute for Human Development, Berlin

${ }^{2}$ Free University of Berlin \& German Institute for Economic Research (DIW), Berlin

Author Note

Ralph Hertwig ${ }^{(D t t p s: / / o r c i d . o r g / 0000-0002-9908-9556 ~}$

Jan K. Woike https://orcid.org/0000-0002-6816-121X

Jürgen Schupp (iD https://orcid.org/0000-0001-5273-643X

Jan K. Woike is now at the University of Plymouth, UK.

We are grateful to Susannah Goss and Deb Ain for editing the manuscript.

Some of the data and ideas reported in this manuscript were presented at the March 2019

Ernst Strüngmann Forum on Deliberate Ignorance in Frankfurt, Germany. The data analyzed here are available via the German Socio-economic Panel Study (SOEP) at DIW Berlin. Because the direct use of SOEP data is subject to strict provisions of German data protection law, we are not permitted to upload them onto an open science repository. However, the scientific use file of the SOEP with pseudonymized microdata is available free of charge to universities and research institutes for research and teaching purposes (upon signing a data distribution contract); requests should be mailed to soepmail@diw.de

Correspondence should be addressed to Ralph Hertwig, Center for Adaptive Rationality, Max Planck Institute for Human Development, Lentzeallee 94, 14195 Berlin, Germany. Email: hertwig@mpib-berlin.mpg.de 


\begin{abstract}
People sometimes choose to remain ignorant, even when information comes at low marginal costs and promises high utility. To investigate whether older adults enlist deliberate ignorance more than younger adults, potentially as an emotion-regulation tool, we presented a representative sample of 1,910 residents of Germany with 13 scenarios in which knowledge could result in substantial gains or losses. The strongest correlate of deliberate ignorance was indeed age. Openness to experience was negatively correlated with deliberate ignorance; risk preference did not and neuroticism did not consistently predict it. Findings suggest a possible positivity effect in the decision to access new but ambiguous information.
\end{abstract}

Keywords: deliberate ignorance, uncertainty, emotion regulation, positivity effect, aging 


\section{Aging and Deliberate Ignorance}

The idea that the human thirst for knowledge is noble and boundless runs through the Western history of thought. The first line of Aristotle's Metaphysics reads: “All men, by nature, desire to know" (Ross, 1924, p. 255). The English philosopher Thomas Hobbes placed curiosity among the passions and described it as a kind of "perpetuum mobile of the soul" (Daston \& Park, 2001, p. 307). More recently, psychologists have echoed these views. Maslow (1963), who proposed the hierarchy of needs, portrayed humans as possessing an instinct-like "burning curiosity" (p. 114) and Silvia (2008) has referred to an emotion-like urge to know.

Yet it is easy to find behaviors that challenge this leitmotif of an eternal thirst for knowledge. Neuropsychologist Nancy Wexler, for example, devoted her scientific career to the study of the genetic foundation of Huntington's disease, which had killed her mother and four other relatives. When a chromosomal test had finally been developed, both she and her sister opted not to take it. "We were going to take the test, you know, why not? We were the family that invented it so how could we not take it? And then I started getting nightmares, my sister started getting nightmares, my dad started getting nightmares because you know living with ambiguity is not that bad" (in Mishkin, 2016). Likewise, Nobel laureate James Watson, one of the team who discovered the double helix structure of DNA, decided not to find out whether he had the apolipoprotein E gene, which is the major genetic risk factor for late-onset Alzheimer's disease. Despite agreeing to having his genome sequenced and released, he shielded himself from this information. Another Nobel laureate and author of The Tin Drum, Günter Grass, repeatedly declined to consult the extensive file that the Stasi, East Germany's secret police, had compiled

on him. A frequent visitor to East Germany, Grass did not want to know which of his friends and colleagues had informed on him (Hage \& Thimm, 2010). 
There is one-perhaps coincidental-commonality between Wexler, Watson, and Grass. They were no longer young when they decided against quenching the thirst for knowledge. To what extent is chronological age a correlate of individuals' preferences for knowledge or lack thereof? A study by Gigerenzer and Garcia-Retamero (2017) found some initial evidence for an age effect, with older adults being more likely than younger adults to forgo available knowledge; however, the authors analyzed a coarse and truncated age range (18- to 35-year-olds and over 50year-olds). In this study, we investigated more thoroughly age differences in deliberate ignorance across a wide age range (21-99 years). Before we outline why age may contribute to molding this knowledge preference, let us briefly consider the broader conceptual context of the choice not to know.

\section{The Choice Not to Know}

From a classic economic perspective, Wexler's decision not to take the test for Huntington's appears irrational. This perspective states that individuals derive utility not from beliefs and information per se but from their potential tangible consequences. Consequently, information carries instrumental value only to the extent that it results in better decisions. A straightforward implication is that people should not hesitate to access cost-free (in an economic sense) and valid information unless ignorance of that information confers a strategic advantage (Schelling, 1956). After all, they can always choose to disregard that information. At least, that is the theory. ${ }^{1}$ In practice, the assumption that information can be easily ignored seems psychologically implausible. Would you want to find out whether you carry the gene for a disabling and fatal disease for which there is no treatment or cure? If you found out, could you

\footnotetext{
${ }^{1}$ Some modern economic models do assume that people derive utility from their beliefs (and, by extension, from information) about the states of the world. This notion of belief-dependent utility, however, represents a strong departure from the standard economic approach and its assumption of independence between beliefs and preferences (see Brown \& Walasek, 2020).
} 
continue to live as though nothing had changed? Having recently revealed that she indeed has Huntington's disease, Wexler said: "I don't think I could have lived with that knowledge," underlining that "denial is important" (Grady, 2020).

The desire not to know is a rich human phenomenon that has received growing attention in psychology (e.g., Case et al., 2005; Gigerenzer \& Garcia-Retamero, 2017; Hertwig \& Engel, 2016, 2020), economics (where it is often dubbed "information avoidance"; e.g., Golman et al., 2017), neuroscience (e.g., Charpentier et al., 2018), the social sciences (e.g., Gross \& McGoey, 2015), and public policy making (Hertwig \& Engel, 2020). Hertwig and Engel (2016) recently discussed a range of functions of what they term deliberate ignorance - the deliberate individual or collective choice not to seek or use available information in situations where the marginal acquisition costs are negligible and the benefits potentially large. In situations where both of these conditions - low marginal costs and high potential utility — hold, deliberate ignorance cannot be explained as a rational trade-off between the costs of information search and the potential instrumental value of having that information, as assumed in the classic economics of information (Stigler, 1961; but see Footnote 1). Rather, other motives appear to underlie deliberate ignorance (Hertwig \& Engel, 2016; see taxonomy in their Figure 1), key among them an emotion-regulatory function (see also Golman et al., 2017).

People may decide against acquiring information when the adverse effects of the anticipated negative emotions triggered by one possible outcome (e.g., learning that one carries the Huntington's gene) exceed the value of the anticipated positive emotions triggered by another possible outcome (e.g., learning that one does not carry the Huntington's gene). Avoiding the information, regardless of its outcome, is thus a way of regulating one's emotional well-being. The same logic applies to one specific negative emotion: regret. People may aim to avoid 
anticipated regrets by choosing not to acquire information that could suggest that a different decision (e.g., not taking a genetic test) would have produced a preferable outcome.

\section{Aging, Emotion Regulation, and the Choice Not to Know}

The emotion-regulatory function of deliberate ignorance may become especially pertinent with age. Despite typically experiencing decline in cognitive and physical abilities (Carstensen et al., 1998; Lindenberger, 2014), older adults report higher levels of hedonic wellbeing, lower levels of negative affect, and higher levels of positive affect than do younger adults, at least until very late in life (e.g., Stawski et al., 2008). One influential explanation of this pattem is the positivity effect and, relatedly, older adults' better ability to regulate their emotions. Originally described by Mather and Carstensen (2003, 2005), the positivity effect "refers to an age-related trend that favors positive over negative stimuli in cognitive processing. Relative to their younger counterparts, older people attend to and remember more positive than negative information" (Reed \& Carstensen, 2012, p. 1). This effect has been replicated across numerous studies and several information-processing dimensions, including attention, episodic memory, affective working memory, and autobiographical memory (see also Reed et al., 2014). The positivity effect has been grounded in the framework of socioemotional selectivity theory (Carstensen, 2006), which postulates that these shifts in emotional goals are related to changing time horizons with age.

Can a positivity effect also be observed when older adults have the opportunity to learn new information, and specifically information that is ambiguous insofar as its implications could be (profoundly) negative or positive? If age is associated with a preference for positive over negative material in cognitive processing, older people may be more likely to forgo the opportunity to access new but ambiguous information in order to insulate their thoughts and emotional reactions from knowledge that could have negative consequences or trigger regrets. In 
this sense, a higher prevalence of deliberate ignorance in older age would not necessarily (or, at least, not exclusively) indicate a decline in intellectual curiosity or in openness to experience; rather, it could reflect a focus on emotional goals and be used as a cognitive strategy for managing attention allocation and information intake.

Independently of emotion regulation, age may also shape knowled ge preferences through the propensity to take risks, which typically decreases with age (Josef et al., 2016). Might a higher propensity for deliberate ignorance in older age be associated with or even caused by a decline in risk preference? Gigerenzer and Garcia-Retamero (2017) observed that people who were risk averse for gains and losses were more likely to exercise deliberate ignorance than people who were risk seeking.

Other attributes potentially related to people's desire (not) to know include two Big Five personality dimensions: openness to experience and neuroticism (emotional stability). Openness to experience is itself a form of knowledge preference that can be expected to correlate negatively with deliberate ignorance. Neuroticism, at its core a tendency to experience negative emotional states (e.g., anxiety, self-doubt), has been found to be negatively associated with information seeking behavior (e.g., Halder et al., 2010) but to positively predict health anxiety, which in turn positively predicted online health information seeking (Lagoe \& Atkin, 2015). In light of these mixed results, it is not clear in which direction the relationship between neuroticism and deliberate ignorance points. Both personality dimensions continue to change in adulthood, with people showing increased emotional stability with age, at least through midlife, and significant declines in openness to experience in old age (Roberts \& Mroczek, 2008; Roberts et al., 2006; Specht et al., 2011).

In this study, we therefore investigated age differences in individuals' knowledge preferences and, specifically, to what extent age is associated with higher levels of deliberate 
ignorance. We further examined the association of age differences in deliberate ignorance with risk preference, openness to experience and neuroticism. The study was administered as a special module of a multipurpose survey commissioned by the German Socio-Economic Panel (SOEP), a representative longitudinal study of private households affiliated with the German Institute for Economic Research (DIW) in Berlin. The respondents were recruited by TNS Infratest Sozialforschung, a market and social science research company.

\section{Method}

\section{Participants}

We surveyed 2,005 respondents (986 male, 1019 female, aged 14-99 years). This sample covered residents of Germany aged 14 years and older who live in private households. Respondents were interviewed in their homes via a computer-assisted personal interview (CAPI). First, our sample was regionally stratified. Next, interviewers randomly sampled household addresses using a targeted random walk method (Thompson, 2006). Beginning with specific local addresses, each interviewer contacted every third household. One person aged 14 or older per household was randomly chosen (using the last-birthday method) and interviewed. To correct for nonresponse and other sources of selectivity, we applied individual weights based on the distributions of region, household size, gender, and age (relative to the distributions in the 2015 German Microcensus). Table S1 in the Online Supplement reports the demographic characteristics of the resulting sample, which was not perfectly but approximately representative of the population proportions observed in the 2015 German Microcensus. Note that we removed participants aged 14-20 years $(n=95)$ from all following statistical analyses due to the combination of high developmental heterogeneity in a group encompassing adolescence and young adulthood and a relatively small sample size.

\section{Measures}


The interview covered several subject areas, one of which was deliberate ignorance. We constructed 13 scenarios to probe respondents' knowledge preferences in a range of paradigmatic choice situations. Table 1 summarizes each scenario; the full text is provided in the Online Supplement. For each scenario, respondents were asked to decide: "Would you want to know or would you prefer not to know?" The scenarios, which were developed in German, were designed to capture emotion regulation and avoidance of anticipated regret, one of the major functions of deliberate ignorance (Hertwig \& Engel, 2016). The situations depicted involved the risk of major losses and negative emotions as well as the possibility of major gains (e.g., relief of emotional strain and existential anxieties). For illustration, consider the situation of someone who lived in former East Germany deciding whether or not to read their Stasi file — and potentially discovering that friend s or relatives had informed on them. Under ignorance, they can assume that no such unspeakable breach of trust was committed. Knowledge carries the risk of a great loss (betrayal) and negative feelings (sadness, rage), but also the possibility of alleviating needless doubts and worries (see Ellerbrock \& Hertwig, 2020).

In order to evaluate the internal consistency of our deliberate ignorance scenarios (Cronbach, 1951), we calculate Cronbach's $\alpha$. With Cronbach's $\alpha=.72$, internal consistency was reasonably high, and eliminating any of the 13 scenarios did not increase this value. Note that some participants did not respond to all scenarios (see Result section). When we repeated the analysis, imputing the missing values with the mean value for each scenario, Cronbach's $\alpha$ was unchanged (.72). To further analyze individuals' choice not to know, we also calculated a Deliberate Ignorance (DI) score for each individual (i.e., an index value between 0\% and 100\% per person indicating the number of 'prefer not to know' responses divided by the total number of responses. Cronbach's $\alpha$ for this score was .72. Finally, twelve of the 13 scenarios represented prototypical situations in which deliberate ignorance could be chosen to avoid negative emotions. 
In addition, we also included one recruitment scenario in which deliberate ignorance (of candidates' gender and appearance) served to safeguard impartiality, another of the functions of deliberate ignorance (Hertwig \& Engel, 2016). This 'unbiased selection' scenario permitted us to investigate whether an age effect was unexpectedly observed in a setting with much less potential to elicit (negative) emotions. All participants saw the scenarios in the same randomly determined order.

Further measures assessed sociodemographic information (e.g., age, education, income) and risk attitude. For the latter, we employed a single self-report item probing general risk-taking propensity. It has been used in other analyses on risk taking (e.g., see Josef et al., 2016) and has proved to be more reliable as an index of risk-taking attitude than various behavioral measures of risk preference (Frey et al., 2017, 2020). Finally, respondents completed a short version of the Big Five personality inventory (BFI-S) measuring openness to experience, conscientiousness, extraversion, agreeableness, and neuroticism (see McCrae \& Costa, 2003). The BFI-S is a selfreport questionnaire (three items per dimension) requiring a 1 (does not apply at all) to 7 (applies perfectly) rating. It has shown reasonably high correlations with the original Big Five Inventory (Donnellan \& Lucas, 2008).

\section{Ethics Statement}

DIW Berlin contracted TNS Infratest Sozialforschung GmbH to include the deliberate ignorance module in a multitopic survey. Data collection, processing, and storage were in full accordance with German data protection regulations. The DIW scientific advisory board and SOEP survey committee oversaw the research, and German data privacy laws necessitate that all users sign a data user contract with DIW Berlin. The survey data files are provided in anonymous form only.

\section{Results}


A total of $1,570(82.2 \%)$ participants responded to all scenarios; $340(17.8 \%)$ left out at least one. On average (median), the latter group left out two scenarios and they did so fairly evenly across all scenarios; furthermore, missing values did not cluster with any of the age groups. All results reported here are based on the available responses per scenario.

Deliberate ignorance varied across the scenarios, ranging from a maximum of about $90 \%$ of respondents preferring not to know the exact date of their death to a minimum of about $21 \%$ preferring not to know whether an antique statue they had recently bought was authentic (Table 1). Across all 13 scenarios, the median proportion of respondents who preferred not to know was $51 \%$. Only small proportions of people always preferred to know $(1.2 \%)$ or not to know $(2.8 \%)$.

\section{Relationship of Age and Deliberate Ignorance}

We next examined deliberate ignorance as a function of age. To this end, we first created seven age groups: $21-30$ years, $31-40$ years, .., 81-99 years. The larger range of the highest age group was due to sample size. We expressed the relationship with age in terms of differences relative to the knowledge preferences of the youngest age group. Figure 1 shows the absolute differences in 'prefer not to know' responses as a function of age (in bins) and by scenario. The group aged 51-60 years was the first to show a substantial age-related average difference in the preference not to know. It occurred quite consistently across items, with one exception: As expected, in the 'unbiased selection' scenario (see text in Online Supplement), respondents of all ages had a strong and consistent preference not to know. In other words, this item-as per its design - appears to tap into a different motivation for deliberate ignorance than the other scenarios do (i.e., impartiality and fairness concerns as opposed to emotion regulation; see Hertwig \& Engel, 2016).

Another interesting observation from Figure 1 is that the two scenarios on which the two oldest age groups (71-80 years; 81-99 years) deviated most strongly from the youngest age 
group both related to health ('incurable disease' and 'genetic analysis'). The oldest respondents were much less interested than the youngest respondents in taking a free genetic test; similarly, they had a much stronger preference not to find out in their early 30s whether they carried a genetic mutation for an incurable disease. It thus seems that with a smaller window of time left, people prefer less to more knowledge about their genetic risk for disease.

A correlational analysis also demonstrated the orderly way in which preference for deliberate ignorance differed as a function of age. Table S2 in the Online Supplement reports the Pearson correlations between the percentages of 'prefer not to know' responses for the 13 scenarios between two given age groups. For instance, the percentage of 'prefer not to know' responses in the 51-60-year-olds strongly correlated with that in the 41-50-year-olds $(r=.98)$. More generally, all correlations were positive and ranged between .86 and .99 . Leaving aside the absolute level of deliberate ignorance, these results suggest that the scenarios that evoke the strongest preference for deliberate ignorance among older adults are, by and large, the same ones that evoke this desire among younger adults. This may be taken as initial evidence that the affective and cognitive mechanisms underlying the preference for deliberate ignorance are robust across age groups.

\section{Relationship of Openness, Neuroticism, and Risk Preference to Deliberate Ignorance}

To examine how deliberate ignorance related to other constructs, we next calculated the Pearson intercorrelations between the four predictor variables (age, risk preference, openness to experience, and neuroticism), two demographic variables (education and income), and the DI score. Table 2 reports the results. In this correlation analysis, the strongest association with the DI score was observed for age. We also observed a substantial negative correlation between age and risk preference, consistent with the finding that risk-taking propensity typically decreases with age (Josef et al., 2016). Further consistent with past results, we observed a substantial positive 
correlation between openness to experience and risk preference (e.g., Becker et al., 2012).

Finally, we also found a pronounced negative correlation between education and age, an issue to which we return shortly.

We then conducted two regression models with the DI score as the dependent variable. Model 1 considered only the effect of age; Model 2 additionally included risk preference, openness to experience, and neuroticism as predictors. Table 3 presents the unstandardized coefficients and their confidence limits, the standardized coefficients, and (in the note) information on model fit. We first compared a baseline model without predictors (intercept-only model; not shown) with Model 1, in which only age was entered as a predictor. Model 1 provided a better fit to the data, and age explained a significant amount of variance in the preference for deliberate ignorance. Model 2, which included the two personality traits and risk preference as additional predictors, yielded an improvement in fit relative to Model 1 (see note to Table 3), but the main effect of age persisted. Of the additional predictors, openness was negatively related to the preference for deliberate ignorance and neuroticism was positively related to this preference (but note that the $99 \%$ confidence interval, CI, for neuroticism overlapped zero, indicating lack of significance).

Finally, we turned to the potential impact of income and education on deliberate ignorance. As is apparent from Table 2, in general, the older adults in our sample had a lower level of education than the younger adults. This finding reflects the expansion of higher education in post-war Germany from an opportunity reserved for a privileged elite to a chance for many (e.g., only $6.4 \%$ and $3.2 \%$ of male and female school leavers, respectively, qualified for higher education in 1950, compared with $21.1 \%$ and $28 \%$, respectively, by 2000; Rahlf, 2015). For this reason, and because education and income were correlated with the DI score (Table 2), we conducted an additional hierarchical regression analysis including education and income. This 
analysis is reported in Table S3 in the Online Supplement. Comparison of this full model with the analysis in Table 3 shows that the conclusions for the impact of age and openness to experience on deliberate ignorance remain unchanged. Neuroticism was no longer a significant predictor (at both the $95 \%$ and $99 \%$ confidence interval) and income predicted deliberate ignorance insofar as higher income was associated with a lower DI score.

\section{Discussion}

Why is the preference for deliberate ignorance more pronounced in older age? One possible explanation is that age is associated with systematic changes in the key personality trait

of openness to experience. People who score high on openness are generally receptive to new and challenging thoughts, emotions, and facets of cultural life (McCrae \& Costa, 2003), and our scenarios may invoke challenging knowledge and emotions. Openness has been found to decline with age. Thus, a stronger preference for deliberate ignorance in older age could potentially be driven by declining openness. In our data, however, the correlation of age and openness was just -.10 (Table 2). That is, the two variables appear to contribute largely independently to the preference for deliberate ignorance, with age being by far the strongest predictor (see $\beta$ values in Table 3).

Education and income were also correlated with the choice not to know (Table 2). Additional regression analyses (Table S3) showed that, independently of age, they explained some variance but age remained the strongest predictor. Another possible explanation of this relationship is that deliberate ignorance is driven by shifts in motivational priorities and information processing in old age. According to socioemotional selectivity theory (Carstensen, 2006), when people perceive their future as wide open (e.g., in early adulthood), they tend to prioritize future-oriented goals, including acquiring information, extending their social network, and expanding their intellectual horizons. As people age and their time horizon narrows, they 
begin to prioritize present-focused goals pertaining to emotional meaning and satisfaction. Furthermore, socioemotional selectivity theory offers a theoretical foundation for the positivity effect - a shift in information processing toward positive material, and away from negative or neutral material, in later life (Reed et al., 2014).

Our study offers an interesting twist on extant investigations of the positivity effect. In the scenarios studied here, the valence of the information is highly uncertain - it could turn out to be positive or negative. A positivity effect in the acquisition of such ambiguous information could mean that that older people actively prioritize reducing the risk of receiving potentially negative information, even if doing so means forgoing the opportunity of receiving positive or even liberating information. This possibility has interesting implications. For instance, younger adults may decide to acquire knowled ge that their elder selves would renounce-knowled ge that they may later even regret, especially if the outcomes of their decision materialize only in the distant future (see Zeelenberg, 1999). Had Nancy Wexler been able to take a Huntington's test as a young woman, she might have chosen to do so, possibly leaving her older self to regret that decision years later (see, however, McCloud et al., 2013, who found that younger cancer survivors were more likely to avoid cancer-related information; moreover, many who belong to the risk group for Huntington's disease decide not to take the test; Creighton et al., 2003; Yaniv et al., 2004).

There is another potential explanation for deliberate ignorance being more pronounced in older age. Older adults' shorter remaining life expectancy may lower the expected utility of the information, leading them to choose not to acquire it. Indeed, the two scenarios on which the two oldest age groups (71-80 years, 81-99 years) deviated most strongly from the youngest age group both related to health: The oldest respondents were much less interested than the youngest respondents in taking a free genetic test or finding out whether they carried a genetic mutation for 
an incurable disease. We cannot exclude the possibility that in these scenarios the perceived utility was lower for older people than for younger people. It is worth keeping in mind, however, that older adults may value the opportunity to find out about genetic risk factors to the extent that having this knowledge may carry substantial utility for their children and grandchildren. It is also possible that shorter remaining life expectancy makes the information in some of our scenarios more valuable - for instance, whether a god-like entity exists or whether an antique statue that may be bequeathed to one's children is authentic. Future studies should therefore elicit respondents' judgments of the utility of the information and experimentally manipulate it.

\section{Limitations and Future Research}

Let us emphasize that our cross-sectional study was not designed to discern the impact of age, cohort, and historical change. Some of the scenarios pertain to historical events (e.g., the fall of the Berlin Wall). Some of the differences observed in deliberate ignorance could therefore be due to cohort effects rather than age effects (see Drewelies et al., 2019). This is certainly an issue that deserves attention in future research. More generally, it remains unclear what kind of cues older and younger adults respond to in the scenarios and how those cues differ across the scenarios. Relatedly, how do people process and weigh these cues to arrive at a decision to know or not to know, and does their processing change with age? An initial Brinley plot analysis (see Online Supplement) suggests that the scenarios that evoke a stronger desire for deliberate ignorance among older adults are the same ones that evoke this desire among younger adults (see also the correlational analysis in Table S2). Clearly, however, more work is needed to reveal the cognitive and affective cues and mechanisms underlying the choice not to know (e.g., through systematic manipulations of the scenarios).

To conclude, people are often depicted as deeply desiring to reduce uncertainty: "an uncertain future leaves us stranded in an unhappy present with nothing to do but wait" (Gilbert, 
2009). If, however, the wait can be made bearable or even pleasant by directing our cognitive and behavioral resources to positive and meaningful aspects of life - and some theories posit that older people are better at this strategic resource allocation - uncertainty in the present may be preferable to what may turn out to be a distressing certainty in the future. 


\section{References}

Becker. A., Deckers, T., Dohmen, T., Falk, A., \& Kosse, F. (2012). The relationship between economic preferences and psychological personality measures. Annual Review of Economics, 4(1), 453-478. https://doi.org/10.1146/annurev-economics-080511-110922

Brown, G. D. A., \& Walasek, L. (2020). Models of deliberate ignorance in individual choice. In R. Hertwig \& C. Engel (Eds.), Deliberate ignorance: Choosing not to know (Strüngmann Forum Reports, Vol. 29, pp. 121-137). MIT Press.

Carstensen, L. L. (2006). The influence of a sense of time on human development. Science, 312(5782), 1913-1915. https://doi.org/10.1126/science.1127488

Carstensen, L. L., Gross, J. J., \& Fung, H. (1998). The social context of emotional experience. In K. W. Schaie \& M. P. Lawton (Eds.), Annual review of gerontology and geriatrics (Vol. 17, pp. 325-352). Springer.

Case, D. O., Andrews, J. E., Johnson, J. D., \& Allard, S. L. (2005). Avoiding versus seeking: The relationship of information seeking to avoidance, blunting, coping, dissonance, and related concepts. Journal of the Medical Library Association, 93(3), 353-362.

Cerella, J., \& Hale, S. (1994). The rise and fall in information-processing rates over the life span. Acta Psychologica, 86(2-3), 109-197. https://doi.org/10.1016/0001-6918(94)90002-7

Charpentier, C. J., Bromberg-Martin, E. S., \& Sharot, T. (2018). Valuation of knowledge and ignorance in mesolimbic reward circuitry. Proceedings of the National Academy of Sciences, 115(31), E7255-E7264. https://doi.org/10.1073/pnas.1800547115

Creighton, S., Almqvist, E. W., MacGregor, D., Fernandez, B., Hogg, H., Beis, J., Welch, J. P., Riddell, C., Lokkesmoe, R., Khalifa, M., MacKenzie, J., Sajoo, A., Farrell, S., Robert, F., Shugar, A., Summers, A., Meschino, W., Allingham-Hawkins, D., Chiu, T., ... \& Hayden, 
M. R. (2003). Predictive, prenatal and diagnostic genetic testing for Huntington's disease: The experience in Canada from 1987 to 2000. Clinical Genetics, 63(6), 462-475. https://doi.org/10.1034/j.1399-0004.2003.00093.x

Cronbach, L. J. (1951). Coefficient alpha and the internal structure of tests. Psychometrika, 16, 297-334. https://doi.org/10.1007/bf02310555

Daston, L., \& Park, K. (2001). Wonders and the order of nature, 1150-1750. Zone Books.

Donnellan, M. B., \& Lucas, R. E. (2008). Age differences in the Big Five across the life span: Evidence from two national samples. Psychology and Aging, 23(3), 558-566. https://doi.org/10.1037/a0012897

Drewelies, J., Huxhold, O., \& Gerstorf, D. (2019). The role of historical change for adult development and aging: Towards a theoretical framework about the how and the why. Psychology and Aging, 34(8), 1021-1039. https://doi.org/10.1037/pag0000423

Ellerbrock, D., \& Hertwig, R. (2020). The complex dynamics of deliberate ignorance and the desire to know in times of transformation. In R. Hertwig \& C. Engel (Eds.), Deliberate ignorance: Choosing not to know (Strüngmann Forum Reports, Vol. 29, pp. 15-34). MIT Press.

Frey, R., Pedroni, A., Mata, R., Rieskamp, J., \& Hertwig, R. (2017). Risk preference shares the psychometric structure of major psychological traits. Science Advances, 3(10), Article e1701381. https://d oi.org/10.1126/sciadv.1701381

Frey, R., Richter, D., Schupp, J., Hertwig, R., \& Mata, R. (2020). Identifying robust correlates of risk preference: A systematic approach using specification curve analysis. Journal of Personality and Social Psychology. Advance online publication. https://d oi.org/10.1037/pspp0000287 
Gigerenzer, G., \& Garcia-Retamero, R. (2017). Cassandra's regret: The psychology of not wanting to know. Psychological Review, 124(2), 179-196. https://doi.org/10.1037/rev0000055

Gilbert, D. (2009, May 20). What you don't know makes you nervous. The New York Times. https://opinionator.blogs.nytimes.com/2009/05/20/what-you-dont-know-makes-younervous/

Golman, R., Hagman, D., \& Loewenstein, G. (2017). Information avoidance. Journal of Economic Literature, 55(1), 96-135. https://doi.org/10.1257/jel.20151245

Grady, D. (2020, March 10). Haunted by a gene. The New York Times. https://www.nytimes.com/2020/03/10/health/huntingtons-disease-wexler.html

Gross, M., \& McGoey, L. (Eds.). (2015). Routledge international handbook of ignorance studies. Taylor and Francis.

Hage, V., \& Thimm, K. (2010, August 20). “The Nobel Prize doesn't inhibit me in my writing." Der Spiegel. https://www.spiegel.de/international/zeitgeist/spiegel-interview-with-guentergrass-the-nobel-prize-doesn-t-inhibit-me-in-my-writing-a-712715.html

Halder, S., Roy, A., \& Chakraborty, P. K. (2017). The influence of personality traits on information seeking behaviour of students. Malaysian Journal of Library \& Information Science, 15(1), 41-53. https://mjlis.um.edu.my/article/view/6721

Hertwig, R., \& Engel, C. (2016). Homo ignorans: Deliberately choosing not to know. Perspectives on Psychological Science, 11, 359-372. https://doi.org/10.1177/1745691616635594 
Hertwig, R., \& Engel, C. (Eds.). (2020). Deliberate ignorance: Choosing not to know.

(Strüngmann Forum Reports, Vol. 29). MIT Press.

Josef, A. K., Richter, D., Samanez-Larkin, G. R., Wagner, G. G., Hertwig, R., \& Mata, R. (2016). Stability and change in risk-taking propensity across the adult lifespan. Journal of Personality and Social Psychology, 111(3), 430-450. https://doi.org/10.1037/pspp0000090

Lagoe, C., \& Atkin, D. (2015). Health anxiety in the digital age: An exploration of psychological determinants of online health information seeking. Computers in Human Behavior, 52, 484-491. https://doi.org/10.1016/j.chb.2015.06.003

Lindenberger, U. (2014). Human cognitive aging: Corriger la fortune? Science, 346(6209), 572578. https://doi.org/10.1126/science.1254403

Maslow, A. H. (1963). The need to know and the fear of knowing. The Journal of General Psychology, 68(1), 111-125. https://doi.org/10.1080/00221309.1963.9920516

Mather, M., \& Carstensen, L. L. (2003). Aging and attentional biases for emotional faces. Psychological Science, 14(5), 409-415. https://doi.org/10.1111/1467-9280.01455

Mather, M., \& Carstensen, L. L. (2005). Aging and motivated cognition: The positivity effect in attention and memory. Trends in Cognitive Sciences, 9(10), 496-502. https://doi.org/10.1016/j.tics.2005.08.005

McCloud, R. F., Jung, M., Gray, S. W., \& Viswanath, K. (2013). Class, race and ethnicity and information avoidance among cancer survivors. British Journal of Cancer, 108(10), 19491956. https://doi.org/10.1038/bjc.2013.182

McCrae, R. R., \& Costa, P. T. (2003). Personality in adulthood: A five-factor theory perspective (2nd ed.). Guilford Press. https://doi.org/10.4324/9780203428412 
Mishkin, B. (2016, April 4). Oneone1 Profile: Geneticist Dr. Nancy Wexler leads the fight against a dreaded disease she's at risk of developing. Time Warner Cable News NY1.

https://www.ny1.com/nyc/all-boroughs/one-on-1/2016/04/4/one-on-1 -profile--geneticist-dr-nancy-wexler-lead s-the-fight-against-one-of-the-world-s-most-dreaded-hered itary-diseases

Rahlf, T. (Ed.). (2015). Deutschland in Daten. Zeitreihen zur Historischen Statistik [Germany in data: Historical statistics from time series data]. Bundeszentrale für politische Bildung. http://www.bpb.de/shop/buecher/zeitbilder/211002/deutschland-in-daten

Reed, A. E., \& Carstensen, L. L. (2012). The theory behind the age-related positivity effect. Frontiers in Psychology, 3, Article 339. https://doi.org/10.3389/fpsyg.2012.00339

Reed, A. E., Chan, L., \& Mikels, J. A. (2014). Meta-analysis of the age-related positivity effect: Age differences in preferences for positive over negative information. Psychology and Aging, 29(1), 1-15. https://doi.org/10.1037/a0035194

Roberts, B. W., \& Mroczek, D. (2008). Personality trait change in adulthood. Current Directions in Psychological Science, 17(1), 31-35. https://doi.org/10.1111/j.1467-8721.2008.00543.x

Roberts, B. W., Walton, K. E., \& Viechtbauer, W. (2006). Patterns of mean-level change in personality traits across the life course: A meta-analysis of longitudinal studies. Psychological Bulletin, 132(1), 1-25. https://doi.org/10.1037/0033-2909.132.1.1

Ross, W. D. (Ed.). (1924). Aristotle's metaphysics. Clarendon Press.

Schelling, T. C. (1956). An essay on bargaining. The American Economic Review, 46(3), 281306.

Silvia, P. J. (2008). Interest: The curious emotion. Current Directions in Psychological Science, 17(1), 57-60. https://doi.org/10.1111/j.1467-8721.2008.00548.x 
Specht, J., Egloff, B., \& Schmukle, S. C. (2011). Stability and change of personality across the life course: The impact of age and major life events on mean-level and rank-order stability of the Big Five. Journal of Personality and Social Psychology, 101(4), 862-882. https://doi.org/10.1037/a0024950

Stawski, R. S., Almeida, D. M., Sliwinski, M. J., \& Smyth, J. M. (2008). Reported exposure and emotional reactivity to daily stressors: The roles of adult age and global perceived stress. Psychology and Aging, 23(1), 52-61. https://doi.org/10.1037/0882-7974.23.1.52

Stigler, G. J. (1961). The economics of information. The Journal of Political Economy, 69(3), 213-225. https://doi.org/10.1086/258464

Thompson, S. K. (2006). Targeted random walk designs. Survey Methodology, 32(1), 11-24.

Yaniv, I., Benador, D., \& Sagi, M. (2004). On not wanting to know and not wanting to inform others: Choices regarding predictive genetic testing. Risk, Decision and Policy, 9(4), 317336. https://doi.org/10.1080/14664530490896573

Zeelenberg, M. (1999). Anticipated regret, expected feedback and behavioral decision making. Journal of Behavioral Decision Making, 12(2), 93-106. https://d oi.org/10.1002/(SICI)1099-0771(199906)12:2<93::AID-BDM311>3.0.CO;2-S 


\section{Figure 1}

Average Differences in 'Prefer Not To Know' Responses as a Function of Chronological Age, Separately for all 13 Scenarios (Filled Dots) and Averaged Across all Scenarios (Open Squares and Solid Line).

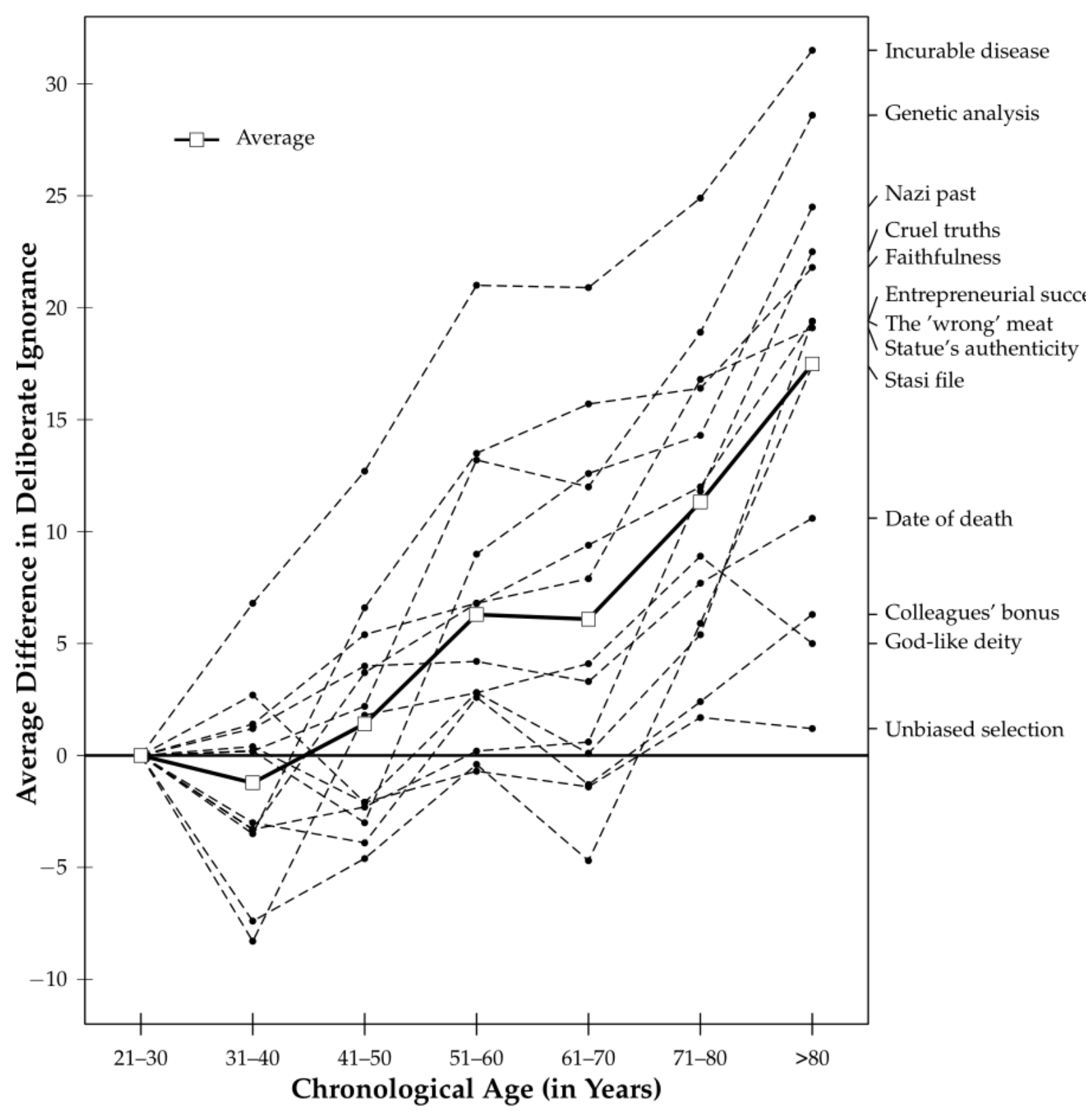

Note. Chronological age was split into seven bins. Differences are shown relative to the responses of the youngest age group (21-30 years); the age group 14-20 years was removed from the analysis (see text). The full text of the scenarios is provided in the Online Supplement. 


\section{Table 1}

The 13 Deliberate Ignorance Scenarios

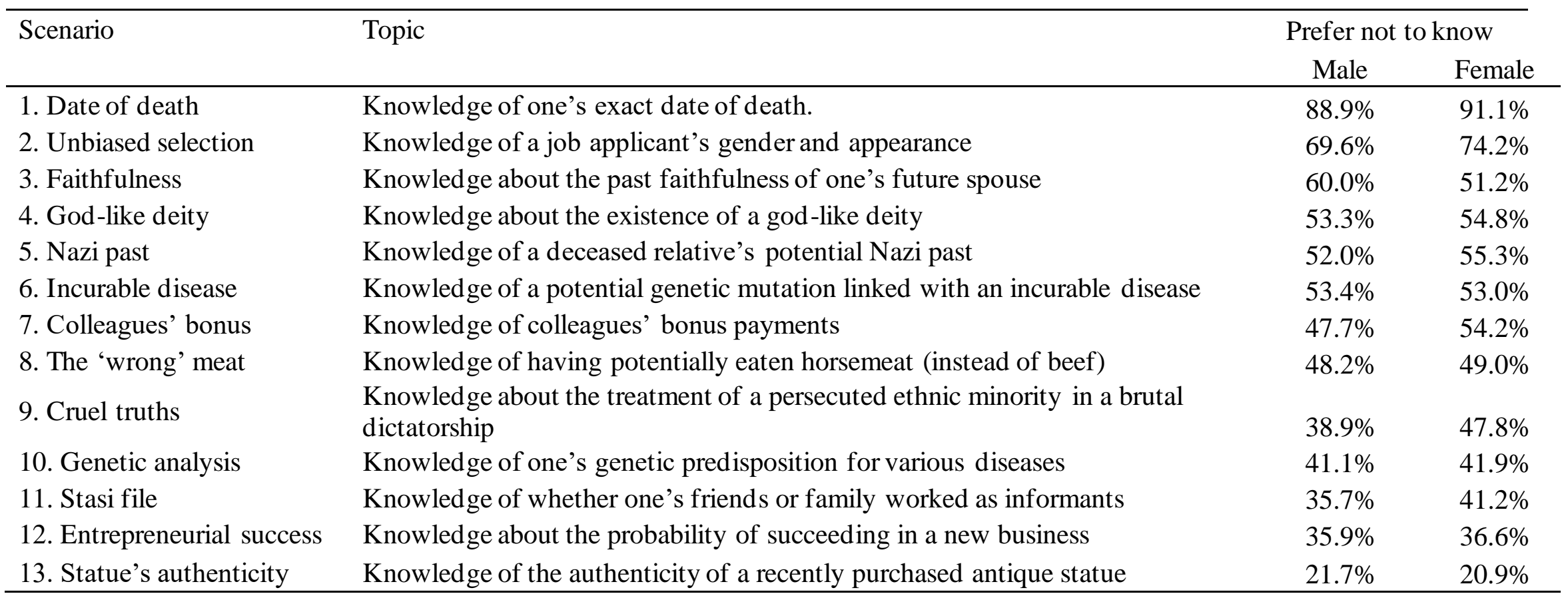




\section{Table 2}

Descriptive Statistics for and Intercorrelation Matrix of Predictors, Demographic Variables, and Criterion (Individuals' DI Score)

\begin{tabular}{lrrrrrrrr}
\hline & $M$ & \multicolumn{1}{c}{$S D$} & 1 & 2 & 3 & 4 & 5 & 6 \\
\hline 1. DI score & 50.9 & 22.94 & & & & & & \\
2. Age & 54.4 & 18.25 & $.21^{* * *}$ & & & & & \\
3. Openness to & 4.6 & 1.19 & $-.13^{* * *}$ & $-.10^{* * *}$ & & & & \\
$\quad$ experience & & & & & & & & \\
4. Neuroticism & 3.7 & 1.15 & $.06^{* *}$ & .01 & -.02 & & & \\
5. Risk preference & 5.5 & 2.40 & $-.10^{* * *}$ & $-.24^{* * *}$ & $.29^{* * *}$ & $-.16^{* * *}$ & & \\
6. Education & 3.6 & 1.64 & $-.15^{* * *}$ & $-.29^{* * *}$ & $.25^{* * *}$ & $-.07^{* *}$ & $.19^{* * *}$ & \\
7. Net monthly & 13.9 & 9.39 & $-.10^{* * *}$ & $.09^{* * *}$ & $.15^{* * *}$ & $-.16^{* * *}$ & $.19^{* * *}$ & $.27^{* * *}$ \\
$\quad$ income (in $100 €$ ) & & & & & & & & \\
\hline
\end{tabular}

Note. Pearson correlations; $1847<N<1910 ;{ }^{* *} p<.01 ;{ }^{* * *} p<.001$; two-tailed. 


\section{Table 3}

Results for Linear Regression Models With Inclusion of Independent Variables Possibly Accounting for Individuals' DI Scores

\begin{tabular}{|c|c|c|c|c|c|c|c|}
\hline \multirow[b]{2}{*}{ Model and predictors } & \multicolumn{2}{|c|}{ Unstandardized } & \multicolumn{2}{|c|}{ Lower (B) } & \multicolumn{2}{|c|}{ Upper (B) } & \multirow{2}{*}{$\begin{array}{r}\text { Stand. } \\
\beta\end{array}$} \\
\hline & $B$ & $S E$ & $99 \% \mathrm{CI}$ & $95 \% \mathrm{CI}$ & $95 \% \mathrm{CI}$ & $99 \% \mathrm{CI}$ & \\
\hline \multicolumn{8}{|l|}{ Model 1: Age } \\
\hline Constant & 35.83 & 1.63 & 31.61 & 32.62 & 39.03 & 40.04 & \\
\hline Age & 0.28 & 0.03 & 0.20 & 0.22 & 0.33 & 0.35 & 0.22 \\
\hline \multicolumn{8}{|c|}{ Model 2: Age + personality + risk } \\
\hline Constant & 42.81 & 3.46 & 33.88 & 36.02 & 49.60 & 51.73 & \\
\hline Age & 0.26 & 0.03 & 0.19 & 0.20 & 0.32 & 0.34 & 0.21 \\
\hline $\begin{array}{l}\text { Openness to } \\
\text { experience }\end{array}$ & -2.05 & 0.45 & -3.22 & -2.94 & -1.16 & -0.87 & -0.11 \\
\hline Neuroticism & 1.03 & 0.45 & -0.13 & 0.15 & 1.92 & 2.20 & 0.05 \\
\hline Risk preference & -0.09 & 0.23 & -0.69 & -0.55 & 0.37 & 0.51 & -0.01 \\
\hline
\end{tabular}

Note: DI score: Percentage of answered items for each respondent. Table shows unstandardized and standardized coefficients and upper and lower limits of the 95\% confidence interval (CI) and the 99\% CI. Model fit results: Model 1: $R^{2}=.048 ; F(1,1843)=93.73, p<.001$. Model 2: $\Delta R^{2}=.015 ; F(3,1840)=9.80, p<.001$. 


\section{Online Supplement}

\section{The 13 Scenarios Employed}

1. Date of death

Suppose you could find out the precise date of your death. Would you want to know or would you prefer not to know?

2. Unbiased selection

Suppose you are a member of a renowned classical orchestra that is searching for a new musician. The auditioning musicians play behind a screen. In the final round, the choice boils down to two candidates, who are asked to play again. Before making your decision, you could have the screen removed to reveal both the gender and the appearance of the applicants.

Would you want to know or would you prefer not to know?

\section{Faithfulness}

Suppose you are going to get married tomorrow. You happen to overhear a conversation about your future spouse. It's all about their previous relationships and how faithful they were in those relationships.

Would you want to know or would you prefer not to know?

\section{God-like deity}

Suppose science will soon be able to determine conclusively whether a god-like entity does or does not exist.

Would you want to know or would you prefer not to know? 
5. Nazi past

Suppose a close relative of yours has recently died. He grew up during the Nazi era but never spoke about that time or his experiences. By consulting his personal papers, such as his diaries, you could find out whether he was a member of a Nazi organization.

Would you want to know or would you prefer not to know?

\section{Incurable disease}

Some genetic disorders are currently incurable and reduce life expectancy. Symptoms typically occur between the ages of 35 and 45 . Suppose you are in your early 30 s and have the opportunity to take a genetic test to find out whether you carry a genetic mutation for an incurable disease.

Would you want to know or would you prefer not to know?

\section{Colleagues' bonus}

Suppose you work in a harmonious and productive team. At the end of the year, each team member receives a bonus. However, some members of the team get a larger bonus than others. The reason is that the management bases the size of the bonus on how important they consider each team member's contribution to the overall outcome to be. The management offers to disclose the actual amounts paid out.

Would you want to know or would you prefer not to know?

8. The 'wrong' meat

The horsemeat scandal of 2013 affected the whole of Europe. Millions of meat products were recalled because horsemeat had been falsely declared as beef. Suppose you regularly eat beef products and could find out whether you had bought and eaten horsemeat instead of beef.

Would you want to know or would you prefer not to know? 
9. Cruel truths ${ }^{2}$

Suppose you live under a brutal dictatorship. Your uncle is a high-ranking member of the regime.

He tells you that he knows what happens to members of a persecuted ethnic minority.

Would you want to know or would you prefer not to know?

10. Genetic analysis

Genetic testing can determine an individual's risk of developing coronary heart disease,

Parkinson's disease, rheumatoid arthritis, certain types of cancer, and type 2 diabetes. Suppose you had the possibility to be tested free of charge to find out your personal risk of future disease.

Would you want to know or would you prefer not to know?

11. Stasi file

Suppose you had lived in East Germany as an adult. By consulting your Stasi file, you would be able to find out whether close friends or family members worked as Stasi informants and spied on you.

Would you want to know or would you prefer not to know?

\section{Entrepreneurial success}

Suppose you want to open your own restaurant; something you have always dreamt of. You could find out how many newly opened restaurants on average go out of business within a year.

Would you want to know or would you prefer not to know?

\footnotetext{
${ }^{2}$ In addition to challenging emotions (e.g., guilt, responsibility), this scenario also invokes a strategic dimension of deliberate ignorance, namely, that of eschewing responsibility (Hertwig \& Engel, 2016).
} 
13. Statue's authenticity

Suppose you are interested in art and have bought an expensive antique statue. Its authenticity was confirmed when you bought it. A friend of yours is a respected expert on ancient art. She offers to examine the statue to determine whether it is truly authentic or not.

Would you want to know or would you prefer not to know? 


\section{Table S1}

Demographic Characteristics of the Sample

\begin{tabular}{|c|c|c|c|c|}
\hline \multirow{2}{*}{ Variable } & & \multicolumn{2}{|c|}{ Sample } & \multirow{2}{*}{$\begin{array}{r}\text { Populat } \\
\% T o\end{array}$} \\
\hline & & $N$ & $\%$ Total & \\
\hline Total & & 2,005 & 100.0 & \\
\hline \multicolumn{5}{|l|}{ Gender } \\
\hline & Male & 986 & 49.2 & 49.0 \\
\hline & Female & 1,019 & 50.8 & 51.0 \\
\hline \multicolumn{5}{|c|}{ Age (in years) ${ }^{b}$} \\
\hline & $14-20$ & 95 & 4.7 & 8.1 \\
\hline & $21-30$ & 261 & 13.0 & 14.0 \\
\hline & $31-40$ & 236 & 11.8 & 13.9 \\
\hline & $41-50$ & 296 & 14.8 & 16.6 \\
\hline & $51-60$ & 339 & 16.9 & 17.6 \\
\hline & $61-70$ & 338 & 16.9 & 12.6 \\
\hline & $71-80$ & 318 & 15.9 & 11.5 \\
\hline & $>80$ & 122 & 6.1 & 5.6 \\
\hline
\end{tabular}

Marital Status

$\begin{array}{llll}\text { Single } & 519 & 25.9 & 33.4 \\ \text { Married }^{c} & 1,028 & 51.3 & 50.2 \\ \text { Widowed } & 233 & 11.6 & 7.9 \\ \text { Divorced } & 214 & 10.7 & 8.6 \\ \text { Missing } & 11 & 0.5 & 0.0\end{array}$

Education $^{\mathrm{d}}$

$\begin{array}{llll}\text { Low level } & 644 & 33.0 & 38.7 \\ \text { Medium level } & 801 & 41.0 & 30.7 \\ \text { High level } & 508 & 26.0 & 30.6\end{array}$

Income

$\begin{array}{lrr}0-499 & 266 & 13.3 \\ 500-999 & 433 & 21.6 \\ 1,000-1,499 & 477 & 23.8 \\ 1,500-1,999 & 849 & 18.6 \\ 2,000-2,999 & 324 & 16.2 \\ >=3,000 & 133 & 6.6\end{array}$




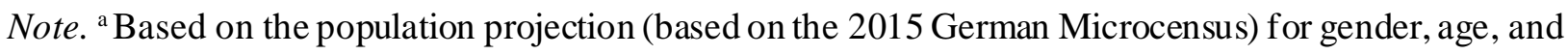
marital status and education ${ }^{\mathrm{b}}$ The age group 14-20 years was removed from all statistical analyses due to the combination of a relatively small sample size and high developmental heterogeneity in this group encompassing adolescence and young adulthood. ${ }^{\mathrm{c}}$ Including cohabitation. ${ }^{\mathrm{d}}$ For nonstudents only; low: e.g., left school without qualifications, left school after 9-10 years; medium: e.g., qualified to study at college/university of applied sciences; high: e.g., completed upper secondary education, graduated from college or university. ${ }^{e}$ Personal monthly net income in EUR: for the purpose of statistical analyses, monthly income was coded in 19 intervals; intervals were represented by their lower limits. 
Table S2

Intercorrelation Matrix of Percentages of 'Prefer Not to Know'Responses Across the 13

Scenarios for Any Two Age Groups

\begin{tabular}{llllllll}
\hline & & 1 & 2 & 3 & 4 & 5 & 6 \\
\hline 1. & $21-30$ years (reference) & & & & & & \\
2. & $31-40$ years & .98 & & & & & \\
3. & $41-50$ years & .96 & .97 & & & & \\
4. & $51-60$ years & .94 & .96 & .98 & & & \\
5. & $61-70$ years & .91 & .94 & .96 & .99 & & \\
6. & $71-80$ years & .93 & .96 & .97 & .99 & .98 & \\
7. & $81-99$ years & .87 & .86 & .90 & .93 & .92 & .94 \\
\hline
\end{tabular}

Note. Pearson correlations; $N=13$; all $p \mathrm{~s}<.001$, two-tailed. 


\section{Additional regression models with income and education}

We conducted an additional hierarchical regression analysis to examine the extent to which age explained variance that was not accounted for by either education or income. The analysis consisted of three consecutive linear regressions starting with education and income in the first step, adding age in the second step, and the remainder of the original variables in the third step to test the robustness of our previous findings (see Table S3). The model fits indicate that age explained variance above and beyond education and income. Comparing the full model with the model reported in Table 3 in the main text, the interpretation for age and openness to experience remains unchanged. In contrast, both confidence intervals for the neuroticism parameter overlapped zero in the full model. In addition, income was found to explain unique variance, and higher income was related to lower DI scores. 


\section{Table S3}

Results for Linear Regression Models With Inclusion of Independent Variables Possibly Accounting for Individuals' DI Scores

\begin{tabular}{|c|c|c|c|c|c|c|c|}
\hline \multirow[b]{2}{*}{ Model and Predictors } & \multicolumn{2}{|c|}{ Unstandardized } & \multicolumn{2}{|c|}{ Lower (B) } & \multicolumn{2}{|c|}{ Upper (B) } & \multirow{2}{*}{$\begin{array}{r}\text { Stand. } \\
\beta\end{array}$} \\
\hline & $B$ & $S E$ & $99 \% \mathrm{CI}$ & $95 \% \mathrm{CI}$ & $95 \% \mathrm{CI}$ & $99 \% \mathrm{CI}$ & \\
\hline \multicolumn{8}{|l|}{ Model 1: Education + Income } \\
\hline Constant & 60.11 & 1.36 & 56.59 & 57.43 & 62.78 & 63.62 & \\
\hline Education & -1.89 & 0.33 & -2.75 & -2.54 & -1.24 & -1.03 & -0.14 \\
\hline Income & -0.17 & 0.06 & -0.32 & -0.29 & -0.06 & -0.02 & -0.07 \\
\hline \multicolumn{8}{|c|}{ Model 2: Age + Education + Income } \\
\hline Constant & 43.29 & 2.31 & 37.34 & 38.77 & 47.82 & 49.24 & \\
\hline Age & 0.27 & 0.03 & 0.19 & 0.21 & 0.33 & 0.35 & 0.21 \\
\hline Education & -0.90 & 0.34 & -1.78 & -1.57 & -0.22 & -0.01 & -0.06 \\
\hline Income & -0.27 & 0.06 & -0.42 & -0.39 & -0.16 & -0.12 & -0.11 \\
\hline \multicolumn{8}{|c|}{$\begin{array}{c}\text { Model 3: Age + Education + Income } \\
\text { + Personality + Risk }\end{array}$} \\
\hline Constant & 46.53 & 3.65 & 37.12 & 39.37 & 53.69 & 55.94 & \\
\hline Age & 0.27 & 0.03 & 0.19 & 0.21 & 0.33 & 0.35 & 0.21 \\
\hline Education & -0.66 & 0.35 & -1.56 & -1.34 & 0.03 & 0.24 & -0.05 \\
\hline Income & -0.24 & 0.06 & -0.40 & -0.36 & -0.13 & -0.09 & -0.10 \\
\hline $\begin{array}{l}\text { Openness to } \\
\text { experience }\end{array}$ & -1.63 & 0.46 & -2.82 & -2.54 & -0.73 & -0.44 & -0.09 \\
\hline Neuroticism & 0.72 & 0.45 & -0.46 & -0.72 & 1.61 & 1.88 & 0.04 \\
\hline Risk preference & 0.10 & 0.23 & -0.51 & -0.36 & 0.56 & 0.70 & 0.01 \\
\hline
\end{tabular}


Note: DI score: Percentage of answered items for each respondent. Table shows unstandardized and standardized coefficients and upper and lower limits of the 95\% confidence interval (CI) and the 99\% CI. Model fit results: Model 1: $R^{2}=.029 ; F(2,1836)=27.29, p<.001$. Model 2: $\Delta R^{2}=.040 ; F(1,1835)=79.81, p<.001$. Model $3: \Delta R^{2}=.008 ; F(3,1832)=5.01, p=.002$ 


\section{Brinley plot analysis}

Our analysis in Figure S1 was inspired by the Brinley plots often used in the cognitive aging literature (e.g., Cerella \& Hale, 1994). Specifically, we first we plotted the percentage of 'prefer not to know' responses per scenario of the six older age groups against those of the youngest age group (21-30 years; see Figure 1). We next regressed the percentages across scenarios for each age group on those of the referential youngest age group and plotted the resulting linear fit lines in Figure S1. With the exception of the two age groups in the middle (5160 years and 61-70 years), the lines lie systematically on top of each other, indicating that the deliberate ignorance scores (DI scores) — the percentage of 'prefer not to know' responses amongst all scenarios for which an individual provided a response-increased monotonically with age and across the scenarios. All regression lines converge in the right upper corner of Figure S1. This is due to the 'date of death' scenario, for which all groups show near-universal agreement in not wanting to know. One scenario elicited almost no dispersion in the responses across age groups (see the data points in the shaded rectangle in Figure S1). As expected, in this 'unbiased selection' scenario, respondents of all ages had a strong and consistent preference not to know. 


\section{Figure S1}

Average Percentage 'Prefer Not To Know' Responses Across 13 Scenarios in Six Age Groups Plotted Against 'Prefer Not To Know' Responses in the Youngest Age Group (21-30 Years)

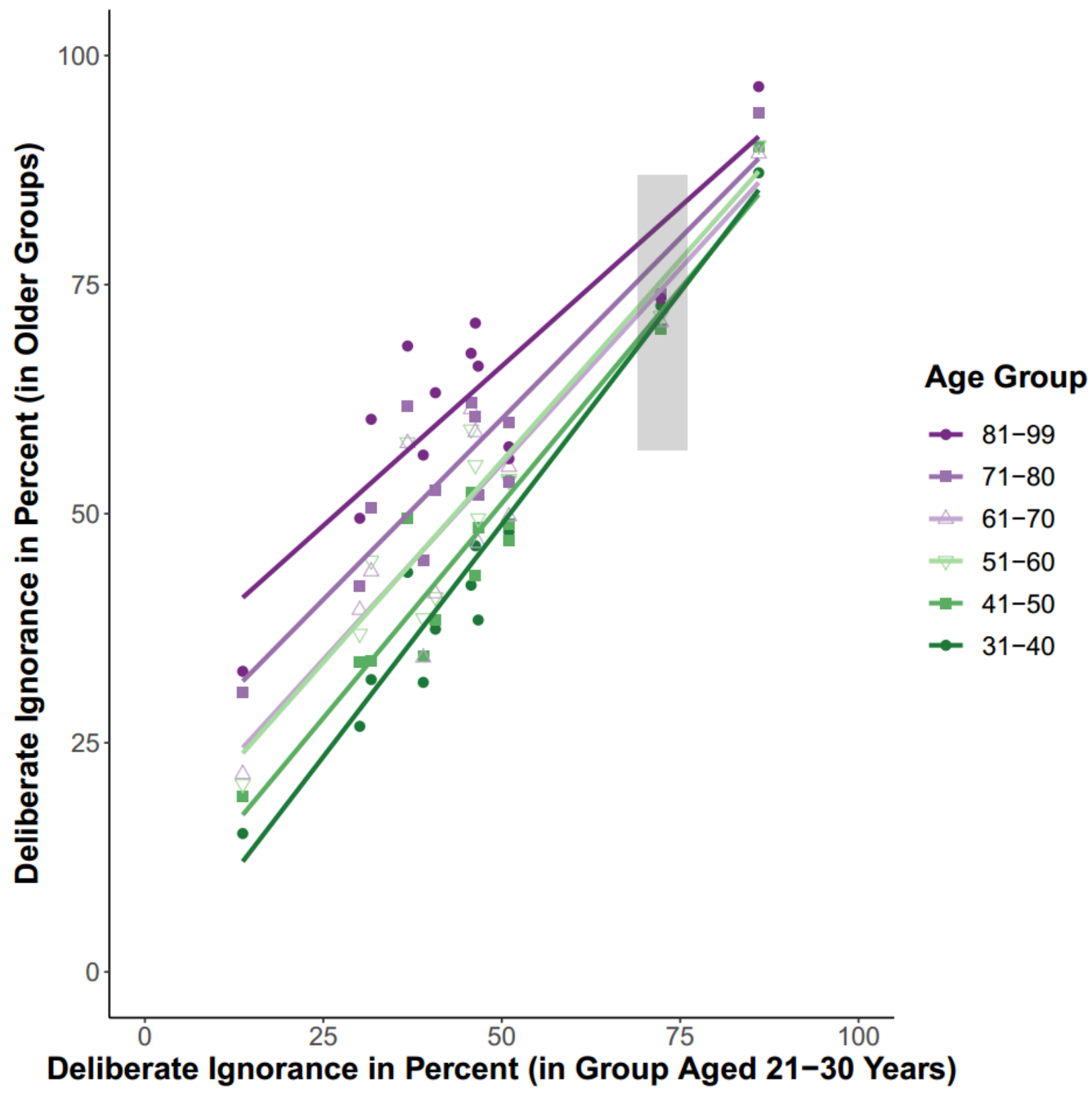

Note. Circles, squares, and triangles represent percentage pairs for individual scenarios; lines are fitted linear regression lines (based on the percentages of 'prefer not to know' responses to the 13 scenarios in the 20-30 years age group, the reference age group). 